\title{
化学結合型シリカゲルを固相抽出剤に用いた固相抽出／ ICP-MSによる高純度鉄中微量元素の定量
}

\author{
長谷川 信一*·井出 邦和 $* \cdot$ 小林 剛 $* \cdot$ 佐藤 幸一 $* 2 \cdot$ 五十嵐 淑郎 $* 3 \cdot$ 内藤 久仁茂 $* 3$
}

Determination of Trace Elements in High Purity Iron by Solid Phase Extraction Using Bonded Silica/ICP-MS

Shin-ichi Hasegawa, Kunikazu Ide, Takeshi Kobayashi, Koichi Sato, Shukuro Igarashi and Kunishige Naito

Synopsis : We attempted a simple pretreating method consisting of solid phase extraction using bonded silica with benzenesulfonic acid (SCX) as the solid phase sorbent to determine trace elements in pure iron samples by means of inductively coupled plasma mass spectrometry (ICP-MS). The isotope dilution method was used along with the method mentioned above to ensure precise determination of $\mathrm{Zn}$. We dissolved the sample of $1.00 \mathrm{~g}$ by nitric acid, subsequently adding citric acid as masking agent. The analytes could be separated by $1-10$ phenanthroline as chelate from the matrix by solid phase extraction after adjusting the $\mathrm{pH}$ and adding 1-10 phenanthroline. The optimum condition for iron separation was $0.01 \mathrm{kmol} \cdot \mathrm{m}^{-3} 1-10$ phenanthroline, $10 \mathrm{~cm}^{3}$; citric acid $(10 \mathrm{w} / \mathrm{v} \%), 10 \mathrm{~cm}^{3} ; \mathrm{pH}, 5.5 ; \mathrm{SCX}, 0.5 \mathrm{~g}$ as the solid phase sorbent; and nitric acid, $2 \mathrm{~cm}^{3}$ as eluate. In this method, some trace elements such as $\mathrm{Ni}, \mathrm{Cu}, \mathrm{Cd}$ and $\mathrm{Zn}$ were determined by ICP-MS using the eluate. The limits of detection in $\mathrm{ng} / \mathrm{g}$ were $\mathrm{Ni} 0.29, \mathrm{Cu} 0.10, \mathrm{Cd} 0.20$ and $\mathrm{Zn} 0.15$. We precisely determined the $\mathrm{Zn}$ content by jointly using the isotope dilution method.

Key words: ICP-MS; isotope dilution; solid phase extraction; bonded silica; 1-10 phenanthroline; trace analysis; pure iron.

\section{1. 緒言}

高純度鉄の研究開発等に関連して，化学分析における定 量下限打よび分析精度の向上が要望され ${ }^{1}$, 多くの超微量 元素分析法の研究が行われている2)。高純度鉄中の微量元 素の定量については黒鉛炉原子吸光法(GF-AAS), 誘導結合 プラズマ発光分析法(ICP-AES), 誘導結合プラズマ質量分析 法(ICP-MS)などが用いられている。

GF-AAS は通常，マトリックスである鉄の分離を行うこ となく酸分解した試料溶液を直接定量できる利点を有す る3,4)。しかし，この方法は単元素定量法であることから， 多元素定量には長時間を要する。更に，一部の高融点元素 や希土類元素には適応できない。他方, ICP-AES は多元素 同時定量法であり，分析適応元素数が多いが, 鉄が共存し た場合，分光干渉などが存在する。そのため一般的にはク ペロン ${ }^{5,6)}$ などを用いた共沈分離，イオン交換分離7)，4-メ チル2-ペンタノンを用いた溶媒抽出分離)などによる鉄の 分離を行っている。また, GF-AAS やICP-MSに比べ検出 感度に劣る。ICP-MS も多元素同時定量法であり, 検出感 度に優れているが，マトリックスが高濃度の場合，スキ マーコーンの目詰まりやメモリー効果により，その後の分 析に悪影響を与える。そのため通常はICP-AES 同様イオン 交換分離8,9等の前処理を必要とする。
著者らは既に，極めて簡単な前処理法 ${ }^{10,11)}$ を用いた ICPMS 法により高純度鉄中微量元素定量法を行い良好な結果 を得た。本研究においても既報と同様に環境等に配慮した 分離法として固相抽出法を適用し, 更なる操作の迅速性, 簡便性を追及した。

固相抽出法は広義にはイオン交換樹脂を用いた分離も含 まれるが, 本研究では樹脂ではなく化学結合型シリカゲ ル 12)を固相抽出剤に用いた。その特徵として，イオン交換 樹脂に比べ粒径が小さく（約 $15 \sim 100 \mu \mathrm{m} ）$, 表面積が大き い。従って, 少ない量の固相抽出剤 $(0.25 \sim 1 \mathrm{~g}$ 程度) で多 量の試料溶液も迅速に分離できる。また，イオン交換樹脂 に比べ異常吸着が少ない。従って少量の溶離液で溶出でき ることから高い比較の濃縮が可能である。

従来, 化学結合型シリカゲルは医薬品, 臨床医学 ${ }^{13)}$, 生 化学 ${ }^{14)}$, 食品分析 ${ }^{15}$, 環境分析 ${ }^{16,17)}$ 等様々な分野で有機化 合物の分離，濃縮に用いられている。しかし，金属分析に おける微量成分定量に用いた報告は著者らの報告 ${ }^{11,18)}$ 以外 見当たらない。そこで，本研究では前報いに引き続き高純 度鉄中の微量不純物元素を錯形成剤と反応させ, 金属錯体 の形で固相抽出骫に保持し，少量の酸で溶出する方法を試 みた。その際，キレート骩には前報で用いたジエチルジチ オカルバミン酸ナトリウム(DDTC)より $\mathrm{pH}$ 調整が容易な110フェナントロリンを用いた。その結果, 高純度鉄中に

平成 15 年 1 月 20 日受付 平成 15 年3月26日受理 (Received on Jan. 20, 2003; Accepted on Mar. 26, 2003)

* 物質 - 材料研究機構 (National Institute for Materials Science, 1-2-1 Sengen Tsukuba 305-0047)

* 2 物質 - 材料研究機構 (現：旭電化工業 (株)) (National Institute for Materials Science, now Asahi Denka Kogyo K.K.)

* 3 茨城大学工学部 (Faculty of Engineering, Ibaraki University) 
含有する微量 $\mathrm{Ni}, \mathrm{Cu}, \mathrm{Zn}$ および Cdの 4 元素について検出限 界 Ni: $0.29, \mathrm{Cu}: 0.10, \mathrm{Zn}: 0.15$ および $\mathrm{Cd}: 0.2 \mathrm{ppb}$ の高感度定 量法を確立した。

さらに，ICP-MSは同位体希釈法(Isotope Dilution Method: ID)による高精度な定量が可能であることから，Znについ ては，本法の分離濃縮技術と同位体希釈 ICP-MS 法(IDICP-MS)を併用した高精度な定量法を検討した。

\section{2. 実験}

\section{$2 \cdot 1$ 装置}

装置は横河アナリティカルシステムズ製PMS2000型 ICP-MS 分析装置を用いた。ネブライザーは Glass Expansion 製同軸型, 溶液フローはマイクロサンプル・ネブライ ザー $\left(300 \mathrm{~mm}^{3} / \mathrm{min}\right)$ を用いた。鉄の定量にはパーキンエル マー社製 5100PC型原子吸光分析装置(AAS) 用い, 光源 には同社製の中空陰極管を用いた。固相抽出操作はジーエ ルサイエンス製GL-SPE吸引マニホールドシステムを用い た。

\section{$2 \cdot 2$ 試薬}

1-10フェナントロリン溶液 $\left(0.01 \mathrm{kmol} \cdot \mathrm{m}^{-3}\right)$ は和光純薬製 1-10フェナントロリン一水和物 $0.9911 \mathrm{~g}$ を硝酸 $0.5 \mathrm{~cm}^{3}$ で溶 解後, 水で希釈して $500 \mathrm{~cm}^{3}$ とした。クエン酸溶液 $(50$ $\mathrm{w} / \mathrm{v} \%)$ は関東化学社製試薬特級のクエン酸 $250 \mathrm{~g}$ を水で溶 解し， $500 \mathrm{~cm}^{3}$ 定容とした。固相抽出剤はバリアン社製 Bond Elute SCX（粒径： $40 \mu \mathrm{m}$ ）を同社製の $10 \mathrm{~cm}^{3}$ ボンド エリュートリザーバーに適量を充填して用いた。固相の上 下にはポリエチレン製のフリットを取り付けた。固相のコ ンディショニングには関東化学社製試薬特級のアセトニト リルおよびMerck社製水酸化ナトリウムを用いた。標準溶 液は関東化学社製原子吸光用標準溶液 $(\mathrm{Mn}, \mathrm{Co}, \mathrm{Cd}, \mathrm{Cu}$, $\mathrm{Ni}, \mathrm{Zn}$ : 各元素 $\left.1 \mathrm{~kg} / \mathrm{m}^{3}(1 \mathrm{mg} / \mathrm{m} l)\right)$ を混合, 希釈し, 各元素 $0.005 \mathrm{~kg} / \mathrm{m}^{3}(5 \mu \mathrm{g} / \mathrm{ml})$ の濃度に調整したもの（6元素混合溶 液) または $\mathrm{Cd}, \mathrm{Cu}, \mathrm{Ni}, \mathrm{Zn}$ : 各元素 $\left.1 \mathrm{~kg} / \mathrm{m}^{3}(1 \mathrm{mg} / \mathrm{ml})\right)$ を混合， 希釈し, 各元素 $0.005 \mathrm{~kg} / \mathrm{m}^{3}(5 \mu \mathrm{g} / \mathrm{m} l)$ の濃度に調整したも の (4元素混合溶液) を用いた。残留した鉄の定量には関 東化学社製原子吸光用 $\mathrm{Fe}$ 標準溶液 $\left(\mathrm{Fe}: 1 \mathrm{~kg} / \mathrm{m}^{3}\right)$ を使用の都 度水で $0.1 \mathrm{~kg} / \mathrm{m}^{3}$ に希釈したものを用いた。濃縮同位体亜鉛 標準溶液は TEKNOLAB A/S 社製 $\left({ }^{67} \mathrm{Zn}: 1 \mathrm{~kg} / \mathrm{m}^{3}\right.$, 純度 $94.50 \%)$ を用いた。鉄溶液 $\left(50 \mathrm{~kg} / \mathrm{m}^{3}\right)$ は日本鉄鋼連盟鉄鋼 認証標準物質 JSS 001-4（高純度鉄 I種）またはJSS 002-4 (高純度鉄 II 種) $5.00 \mathrm{~g}$ を量り取り，硝酸 $10 \mathrm{~cm}^{3}$ を用いて加 熱分解後, 水で希釈し $100 \mathrm{~cm}^{3}$ とした。塩酸, 硝酸および アンモニア水は関東化学社製原子吸光分析用および多摩化 学製TAMAPURE-AA100を用いた。水は蒸留水を藤原製作 所製非沸騰式蒸留水製造装置で更に精製したものを用い た。また, 試薬の調製および試料の分解等はすべてクリー ンベンチ（クラス 100）内で行った。
Table 1. Operating conditions of ICP-MS.

\begin{tabular}{ll}
\hline Rf power & \\
Forward & $1.3 \mathrm{~kW}$ \\
Reflected & $8.0 \mathrm{~W}$ \\
& \\
Gas flow rate & $15.01 \mathrm{~min}^{-1}$ \\
Coolant & $1.21 \mathrm{~min}^{-1}$ \\
Auxiliant & $0.751 \mathrm{~min}^{-1}$ \\
Nebulizer & \\
Nozzle assy & \\
Platinum & $0.9 \mathrm{~mm}$ orifice \\
Skimmer chip & \\
Platinum & $0.5 \mathrm{~mm}$ orifice \\
\hline
\end{tabular}

\section{$2 \cdot 3$ 実験操作}

$2 \cdot 2$ により調製した鉄溶液 $\left(50 \mathrm{~kg} / \mathrm{m}^{3}\right) 20 \mathrm{~cm}^{3}$ を $200 \mathrm{~cm}^{3}$ ビーカーに移し入れ，2·2の 6 元素混合溶液（または 4 元 素混合溶液) およびクエン酸溶液を添加した。これに1-10 フェナントロリン溶液を加え，アンモニア水を用いて $\mathrm{pH}$ を調整した。この溶液をコンディショニングの完了した固 相抽出力ラムに通し，錯体を固相抽出剤に保持させた。水 で数回洗浄後, 溶出液の硝酸を固相抽出力ラムに通過させ 錯体を溶出し，水で数回洗浄した。溶出液および洗液は $100 \mathrm{~cm}^{3}$ メスフラスコに移し入れ定容とした。この溶液を ICP-MSにより Table 1 に示した条件で測定し，検量線法に より元素濃度を算出した。なお，検量線の作成には全操作 を通して得られたブランク溶液を数個用意し，各溶液に 4 元素混合溶液（各元素 $0.005 \mathrm{~kg} / \mathrm{m}^{3}$ ) を $0 \sim 1 \mathrm{~cm}^{3}$ 段階的に添 加し, それぞれ $100 \mathrm{~cm}^{3}$ メスフラスコに移し入れ定容とし たものを用いた。ID-ICP-MSによるZnの定量操作につい ては，鉄溶液 $\left(50 \mathrm{~kg} / \mathrm{m}^{3}\right) 20 \mathrm{~cm}^{3}$ を $200 \mathrm{~cm}^{3}$ ビーカーに移し入 れ，スパイク溶液を添加したものとしないものを調製し， 前述の操作により，固相抽出を行った。スパイク添加と不 添加の同位体組成の変化から試料中の元素濃度を求めた。

固相抽出剤のコンディショニングは初めアセトニトリル $5 \mathrm{~cm}^{3}$ を流し，次に水 $10 \mathrm{~cm}^{3}$ を流した。この操作を 3 回繰り 返した後, $0.1 \mathrm{kmol} \cdot \mathrm{m}^{-3}$ 水酸化ナトリウム溶液 $5 \mathrm{~cm}^{3}$ お び水 $10 \mathrm{~cm}^{3}$ を流し，更に， $0.1 \mathrm{kmol} \cdot \mathrm{m}^{-3}$ 塩酸 $5 \mathrm{~cm}^{3}$, 水 10 $\mathrm{cm}^{3}$ を順次流した。

\section{3. 結果および考察}

\section{$3 \cdot 1$ 分離における $\mathrm{pH}$ の影響}

鉄の吸光光度定量に用いられている1-10フェナントロ リンは Feの他 $\mathrm{Mn}, \mathrm{Co}, \mathrm{Ni}, \mathrm{Zn}, \mathrm{Cd}, \mathrm{Cu}$ などとキレートを作る ことが知られている ${ }^{19)}$ 。しかし, $\mathrm{Fe}^{3+}$ とはフェナントロリ ンキレートをほとんど作らず， $\mathrm{Fe}^{2+}$ のみと作る。そこで， 試料を硝酸で分解することにより鉄を $\mathrm{Fe}^{3+}$ とし, 鉄と目的 元素を分離することにした。

初めに, 最適分離条件決定のため 1-10フェナントロリ ンと目的元素のキレート生成における最適 $\mathrm{pH}$ 域を調べた。 


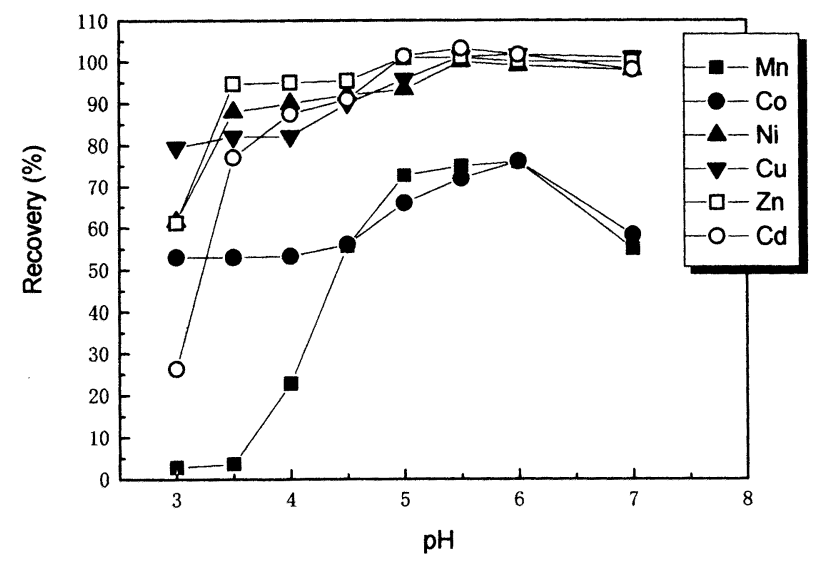

Fig. 1. Effect of $\mathrm{pH}$ on the recovery of analytes.

$2 \cdot 3$ の操作に従って鉄溶液に 6 元素混合溶液, クエン酸お よび1-10フェナントロリン溶液 $10 \mathrm{~cm}^{3}$ 添加した溶液を数個 準備した。アンモニア水を用いてそれぞれの溶液の $\mathrm{pH}$ 1〜7まで段階的に変化させた。これらの溶液を固相抽出力 ラムに通し，金属錯体を固相抽出剤(SCX $0.5 \mathrm{~g}$ ) に吸着させ た。溶離には硝酸 $2 \mathrm{~cm}^{3}$ を用い， $100 \mathrm{~cm}^{3}$ 定容とした。この 溶液と標準溶液を ICP-MS で測定し，各 $\mathrm{pH}$ における目的 元素の回収率を調べた。また，水酸化鉄の生成を抑える目 的で添加したクエン酸は $50 \mathrm{w} / \mathrm{v} \%$ 溶液 $10 \mathrm{~cm}^{3}$ の添加で十分 目的を達成した。結果を Fig. 1に示す。6元素のうちの 4 元 素（Ni, Cu, ZnおよびCd）について pH 5.5で100 103\%の 回収率を示した。Mn 打よびCoは約 75\%の回収率にとど まった。この結果から分離に打ける最適 $\mathrm{pH}$ は 5.5 とした。 なお，前報 ${ }^{11)}$ (キレート剤はDDTCで最適 $\mathrm{pH}$ は 10.6）の 場合と比較すると操作の迅速性はかなり改善できた。

\section{3 -2 1-10フェナントロリン濃度の影響}

$2 \cdot 2$ の鉄溶液 $20 \mathrm{~cm}^{3}$ に 6 元素混合溶液打よびクエン酸溶 液 $10 \mathrm{~cm}^{3}$ を添加した。アンモニア水を用いて $\mathrm{pH}$ を 5.5 に調 整し、これに $0.01 \mathrm{kmol} \cdot \mathrm{m}^{-3} 1-10$ フェナントロリン溶液を 段階的に加え，1-10フェナントロリンの添加量と目的元素 の回収率の関係を調べた。その結果，1-10フェナントロリ ン溶液 $10 \mathrm{~cm}^{3}$ 添加した時に $\mathrm{Ni}, \mathrm{Cu}, \mathrm{Zn}$ および $\mathrm{Cd}$ につてほ ほ $100 \%$ の回収率が得られた。結果を Fig. 2に示す。また， 鉄の残存量をAASにより測定したところ， $0.01 \mathrm{kmol} \cdot \mathrm{m}^{-3}$ 溶液 $1 \mathrm{~cm}^{3}$ 添加では約 $0.002 \mathrm{~kg} / \mathrm{m}^{3}, 5 \mathrm{~cm}^{3}$ 添加時は約 0.008 $\mathrm{kg} / \mathrm{m}^{3}, 10 \mathrm{~cm}^{3}$ では約 $0.017 \mathrm{~kg} / \mathrm{m}^{3}$ と添加量に比例して直線的 に増加した。しかし，この程度の濃度ではICP-MSの測定 に影響を与えることはないと考えられる。

なお，金属キレートを保持した固相抽出郕からの目的元 素の溶出には濃硝酸 $2 \mathrm{~cm}^{3}$ を用いた。溶出液はなるべく少 量で目的元素を溶離できることが濃縮の意味からも望まし いが，1-10フェナントロリンキレートの場合は Fe-フェナ ントロリンキレートの存在により稀硝酸での溶出ではかな りの量を必要とした。

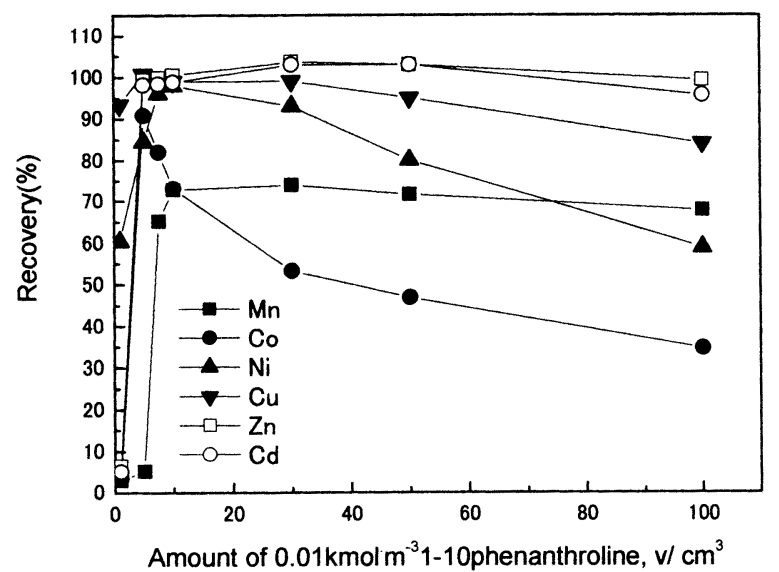

Fig. 2. Effect of 1-10 phenanthroline addition on the recovery of analytes.

Table 2. Limits of detection.

\begin{tabular}{cc}
\hline Elements & $\begin{array}{c}\text { Limits of detection }(3 \sigma) \\
\mathrm{ppb}\end{array}$ \\
\hline $\mathrm{Ni}$ & 0.289 \\
$\mathrm{Cu}$ & 0.098 \\
$\mathrm{Zn}$ & 0.152 \\
$\mathrm{Cd}$ & 0.022 \\
\hline $\mathrm{n}=10$, \\
Limit of detection $=3 \sigma \mathrm{S}-\mathrm{B} \times \mathrm{C}$, \\
$\mathrm{S}:$ count, B: background, C: concentration
\end{tabular}

\section{$3 \cdot 3$ 固相抽出剤の選定と使用量}

固相抽出剤に用いた化学結合型シリカゲルは官能基によ り次の 3 種類に分類される。オクタデシル，オクチルなど の官能基を持つ逆相系，シアノプロピル，ジオールなどの 順相系, ベンゼンスルホン酸, トリメチルアミノプロピル などのイオン交換系である。本研究では1-10フェナント ロリンキレートがプラスの電荷を持つことから固相抽出剤 として陽イオン交換系のベンゼンスルホン酸を官能基に持 つ化学結合型シリカゲル Bond Elute SCXを用いた。また， 固相抽出剤の使用量は保持能力と処理時間に関係する。そ こで，固相抽出時における固相抽出剤の最適使用量を $0.25 \mathrm{~g}$ から $1.0 \mathrm{~g}$ までについて調べた。その結果，この場合 の固相抽出㓲量は $0.25 \mathrm{~g}$ で目的を達成することが分かっ た。しかし，試料により目的元素含有量の高い場合も想定 し，以後の固相抽出剤使用量は $0.5 \mathrm{~g}$ とした。

\section{4 検出限界}

本法における各測定元素の検出限界を Table 2 に示す。 ブランク溶液に 4 元素混合溶液 $10 \mathrm{~cm}^{3}$ 添加し，固相抽出を 行った。検出限界はバックグラウンドの各元素の質量数に おけるイオン強度 $(n=10)$ の標準偏差 $(\sigma)$ の 3 倍を濃度換算 して求めた。 


\section{4. 実際試料の定量}

\section{$4 \cdot 1$ 分析方法}

試料 $1.00 \mathrm{~g}$ を $200 \mathrm{~cm}^{3}$ のビーカーに量り取り, 硝酸 $10 \mathrm{~cm}^{3}$ および水 $10 \mathrm{~cm}^{3}$ で加熱分解する。冷却後， $50 \mathrm{w} / \mathrm{v} \%$ クエン 酸溶液 $10 \mathrm{~cm}^{3}$ および1-10 フェナントロリン溶液 $10 \mathrm{~cm}^{3}$ を加 え穓拌する。アンモニア水を用いて pH 5.5 に調整後, 溶液 を固相抽出剤(SCX $0.5 \mathrm{~g})$ に通過させ錯体を固相抽出剤に捕 集する。固相抽出剤を水で数回洗浄後，洗液は捨てる。次 に，溶出液として硝酸 $2 \mathrm{~cm}^{3}$ を固相に通過させ錯体を溶出 する。水で数回洗浄後, 溶出液および洗液をメスフラスコ に移し入れ $100 \mathrm{~cm}^{3}$ 定容とする。この溶液を ICP-MSに導入 し, Table 1の条件で測定する。検量線から目的元素濃度を 算出する。検量線は全操作を行って得られたブランク溶液 に標準溶液 $0 \sim 10 \mathrm{~cm}^{3}$ を段階的に添加し， $100 \mathrm{~cm}^{3}$ 定容とし た溶液を用いて作製する。ただし，高純度酸や試薬を用い ることにより外部からの污染が少ない（ブランク值が低い） 場合のみ溶出液と同濃度の硝酸に標準溶液を添加して作製 しても良い。

ID-ICP-MSによる $\mathrm{Zn}$ の定量は試料 $1.00 \mathrm{~g}$ を $200 \mathrm{~cm}^{3}$ の ビーカー数個に量り取り，硝酸 $10 \mathrm{~cm}^{3}$ おび水 $10 \mathrm{~cm}^{3}$ で加 熱分解する。一方のビーカーにはスパイク溶液を添加し， もう一方には添加しない。冷却後， $50 \mathrm{w} / \mathrm{v} \%$ クエン酸溶液 $10 \mathrm{~cm}^{3}$ および1-10フェナントロリン溶液 $10 \mathrm{~cm}^{3}$ を加え筧拌 する。これらの溶液を上述の操作に従って固相抽出を行い, 試料溶液を調製する。これらの溶液を ICP-MS に導入測定 し, スパイク添加と不添加の同位体組成の変化から試料中 の $\mathrm{Zn}$ 濃度を求めた。

\section{$4 \cdot 2$ 分析結果}

本法により日本鉄鋼連盟鉄鋼認証標準物質 JSS 002-1, JSS 003-1 およびJSS 003-3の Ni およびCuを，また，JSS 001-4の Znを定量した。結果を Table 3に示す。表示值に対 し良い一致を見た。更に，ID-ICP-MSにより，002-4の Zn を定量したところ定量結果は $0.109 \pm 0.006 \mathrm{ppm}$ であった

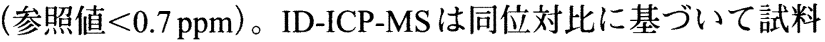

Table 3. Results of the determination of $\mathrm{Cu}, \mathrm{Ni}$ and $\mathrm{Zn}$ in high purity iron by ICP-MS.

\begin{tabular}{lccc}
\hline Sample & Elements & $\begin{array}{c}\text { Certified value } \\
\text { ppm }\end{array}$ & $\begin{array}{c}\text { Found } \\
\text { ppm }\end{array}$ \\
\hline JSS002-1 & $\mathrm{Ni}$ & 9 & 9.5 \\
& $\mathrm{Cu}$ & 4 & 3.8 \\
JSS003-1 & $\mathrm{Ni}$ & 33 & 33.5 \\
& $\mathrm{Cu}$ & 18 & 16.5 \\
JSS003-3 & $\mathrm{Ni}$ & 8 & 8.0 \\
& $\mathrm{Cu}$ & 14 & 13.8 \\
\multirow{2}{*}{ JSS001-4 } & $\mathrm{Zn}$ & 6.8 & 6.85 \\
\hline
\end{tabular}

$n=2$
中の元素濃度を定量する方法であることから，ICP-MSに おけるマトリックス等に起因する信号の増減, 装置のドリ フト等の影響が極めて小さいと考えられる。従って，検量 線法や標準添加法に比べて高精度で正確な定量が可能であ る。

\section{5. 結言}

ICP-MSによる高純度鉄中微量元素定量における前処理 法としてベンゼンスルホン酸を官能基に持つ化学結合型シ リカゲルを固相抽出剤に用いた固相抽出分離の最適分離条 件を検討した。その際，キレート剤およびマスキング剤の 選定とその濃度，分離に最適な $\mathrm{pH}$ 域，固相抽出剤の使用 量，最適な溶出液等を検討した。その結果，キレート剂に は $0.01 \mathrm{kmol} \cdot \mathrm{m}^{-3} 1-10$ フェナントロリン溶液 $10 \mathrm{~cm}^{3}$, マスキ ング剤は $50 \mathrm{vol} \%$ クエン酸 $10 \mathrm{~cm}^{3}$ を用いた。分離に最適な $\mathrm{pH}$ は 5.5 で，固相抽出㓮 $\mathrm{SCX}$ の使用量は $0.5 \mathrm{~g}$ が最適で あった。溶出液は硝酸 $2 \mathrm{~cm}^{3}$ で目的元素を完全に溶出した。 この条件で定量可能な元素は $\mathrm{Ni}, \mathrm{Cu}, \mathrm{Zn}$ および $\mathrm{Cd}$ の 4 元素 であり，検出限界は Ni: $0.29, \mathrm{Cu}: 0.10, \mathrm{Zn}: 0.15$ および Cd: $0.2 \mathrm{ppb}$ であった。更に，本法の分離濃縮技術と基準分析法 としての ID-ICP-MSを併用した Znの定量についての高精 度な定量法を確立した。

\section{文献}

1) K.Abiko: Materia Jpn., 33 (1994), 11

2 ) K.Takada: Materia Jpn., 33 (1994), 84

3 ) T.Kobayashi, S.Hasegawa and T.Yoshioka: Tetsu-to-Hagané, 85 (1999), 124.

4 ) S.Hasegawa, T.Kobayashi and R.Hasegawa: J. Jpn. Inst. Met., 62 (1998), 1163.

5 ) K.Takada, T.Shouji, Y.Danzaki, M.Ishiguro, T.Itagaki and K.Hirokawa: CAMP-ISIJ, 5 (1992), 394.

6 ) 中村佳右, 井出邦和, 長谷川良佑：日本分析化学会第 47 年会 講演要旨集, 日本分析化学会, 東京, (1998), 229.

7 ) K.Yamada, O.Kujirai and R.Hasegawa: Anal. Sci., 9 (1993), 385.

8 ) A.G.Coedo, T.D.López and F.Alguacil: Anal. Chim. Acta, 315 (1995), 331.

9 ) K.Fujimoto and M.Shimura: Bunseki Kagaku, 50 (2001), 175.

10) S.Hasegawa, T.Kobayashi, K.Sato, S.Igarashi and K.Naito: J. Jpn. Inst. Met., 63 (1999), 1069.

11) S.Hasegawa, K.Sato, K.Ide, T.Kobayashi, S.Igarashi and K.Naito: $J$. Jpn. Inst. Met., 64 (2000), 1212.

12) K.C.Van Horne: Sorbent extraction technology, Analytichem International, Inc., Harbor City, (1985), 2.

13) G.Lensmeyer: Clin. Chem., 31 (1985), 196.

14) P.Kao: Clin. Chem., 30 (1984), 56.

15) G.Schieffer, G.Wheeler and C.Cimino: J. Liquid Chromato., 7 (1984), 659.

16) M.D.Müller: Anal. Chem., 59 (1987), 617.

17) J.Szpunar-Łobińska, M.Ceulemans, R.Lobiński and F.C.Adams: Anal. Chim. Acta, 278 (1993), 99.

18) S.Hasegawa, T.Kobayashi, K.Sato, S.Igarashi and K.Naito: J. Jpn Inst. Met., 63 (1999), 1497.

19) F.P.Dwyer and D.P.Mellor: Chelating Agents and Metal Chelates, Academic Press, New York, (1964). 